\title{
Promoting College Students' Innovation and Entrepreneurship by Subject Competition
}

\author{
Yulan Zhao \\ Jilin Agricultural Science and Technology University, Jinlin China \\ Ilbird@126.com
}

Keywords: Subject; Competition; College students; Innovation and entrepreneurship; Ability improvement

\begin{abstract}
With the continuous development of the city, the education of college students is constantly improving. In the process of College Students' learning, for students' innovation and entrepreneurship ability training, For the real society, it is a more realistic problem in the process of training innovative entrepreneurial ability and related subjects, then gradually do the related scientific limited plan. The cultivation of innovative and entrepreneurial ability of the subject competition is to exercise ability through the related subject. This kind of form of ability training is the construction of innovation and Entrepreneurship from three aspects of the content of the subject contest, the form of the subject competition, and the composition of the subject competition. In the process of these subject competition, it is based on the relevant subject knowledge as the foundation of the competition, and then through the mode of competition to cultivate students' ability of innovation and entrepreneurship. In the relevant competition organization, there should be institutionalized, standardized rules to show, so as to effectively ensure the college students' ability of innovate and entrepreneurship to have a greater degree of improvement. In this paper, enhance the related analysis and research on the academic competition to promote the innovation and entrepreneurial ability of college students.
\end{abstract}

\section{Introduction}

In the constant development and construction of real life, the innovation and employment of university students is one of the most concerned problems in the country. This problem is reflected the continuous improvement of the relevant national education system in the education process of college students. In university campus, for the deep level improving of college students' innovation ability cultivation, this improvement reflects the construction of innovation and entrepreneurship knowledge and school and college talent training mode and creating, and in national innovation and entrepreneurship training college planning project. The effective implementation of these rules can help college students in the road of innovation and entrepreneurship to a more perfect advance. In the current education, for students' curriculum planning of entrepreneurship and innovation ability construction is in full swing carried out and many colleges and universities in cultivating college students' innovation ability also has the exploration of the curriculum system and the relevant faculty, gratifying achievements. In the college students' life to cultivate the ability of innovation and entrepreneurship, it is a new mode of training, the construction of the teaching content. The effective promoting related teaching system to a certain situation, the force can be fully displayed in the student's employment situation in the future. The promotion of College Students' innovation ability is not just a perfect discipline, which more is in the construction of College Students' learning and should establish teachers should not only improve of teaching knowledge, should also be in the knowledge teaching of ordered updates and extends, in the system of knowledge teaching gradually on teaching methods and teaching philosophy for further innovation idea construction. In recent years, with the continuous improvement of the national competition system and technology, the role of subject contest in the college students' innovation ability training also cannot be ignored and the discipline competition pattern will gradually become a new station to enhance the students' ability of innovation and entrepreneurship. 


\section{The Present Situation and Future Development of Subject Competition}

With the continuous improvement of China's higher education system, under the current social system and the real life should effectively combine with the higher education system. With the rising of the knowledge economy, the state for innovative talent seek is also increasingly improved, in the previous specialization, the students grew up under the theory of learning mode already cannot adapt to the situation of today's society and life, at the same time, the studying crowd under previous education system, cannot meet the needs of modern society to the degree of talent, especially the current social demand for innovative personnel. Under the social background of reality, the relevant education scholars and experts all have an innovative discussion on the orientation of students' quality education and the requirement of related knowledge quality. In the realistic situation of the promotion, the ability training of university students' innovation and entrepreneurship will gradually become the stage of the new talent training. At the same time, the transformation of this kind of education thought will become the inevitable process of the evolution of higher education thought.

The ability training process of innovation and entrepreneurship will gradually become an established model of higher education in the future, which will gradually be popularized and recognized by the majority of colleges and universities. In the current college education, some colleges and universities opened related courses of innovation entrepreneurship and college students career planning and some universities are offering innovative research institute and the innovation and entrepreneurship practice class, because the university education focused on the aspects of inconsistent phenomenon, result in carrying out in the university life education mode to be not identical. Some pay attention to the cultivation of teaching mode, some focus on the cultivation of teaching methods, and some are related to the construction mode of discipline integration, there is the creation of college students to create innovative practice mode and so on. In the improvement of college teaching, the ultimate goal is to be in the future employment of college students, from the previous job seekers to become the future success of the enterprise.

In the future demand for innovative talents for society, first requirement is the spirit of innovation, innovation personality and innovation ability and in the end should have innovation achievements exhibition. For college students in the university stage of education, the related innovation and entrepreneurial ability is to improve the social situation in accordance with the reality of innovation and entrepreneurship personnel training. This kind of training should be guided by the correct rules and should have the related theoretical construction. Only in this way can we cultivate the ability of College Students' innovation and entrepreneurship in the final training mode, and become the higher talents with the ability of innovation. Such college students in the future life and work, whose concept of self-innovation and entrepreneurial ability can be showed.

The subject competition is a kind of popular science and technology activities for college students. The race is close combination of university curriculum knowledge, and on this basis to effectively enhance a model. The basic theoretical knowledge of the students of some subjects in a contest and the ability to solve problems related to the show. From the relevant data, it can be analyzed and learned that, in the form of competition for this discipline, now many university campuses have been involved in the initial. And this competition is conversing teaching platform from full range, three-dimensional with the advance of time whose process of this transformation can be the ability of university students' innovation and Entrepreneurship and its related teaching mode of reform, the development of practical teaching has a very significant role in promoting.

\section{Optimizing Discipline Competition and Promoting College Students' Ability Cultivation of Innovation and Entrepreneurship}

The form and the related functions of the subject competition determine the talent cultivation in the process of College Students' innovation and entrepreneurship, and the relevant education scholars and experts on the development of the discipline contest has also further explored and tried and gains and achievements. In the practice of discipline competition, under the requirements of the 
competition, the relevant college students' innovation ability is greatly improved, and in cultivating the ability of innovation and entrepreneurship students had more experience and inspiration, but the method of subject competition is a new situation of the teaching practice mode, this model should also be carried out deep research from the content of the subject contest, the content of the subject competition, the form of the discipline competition and the organization of the subject competition. All of the college students' innovation and entrepreneurial ability has a great advantage; these advantages provide a new thinking space for college students' innovation and entrepreneurial ability.

College Students' Subject Competition Based on Their Own Subject Knowledge. In view of the problem that college students' subject competition should be based on their own discipline professional knowledge, first of all, in the process of College Students' innovation and entrepreneurship, the relevant improvement of professional quality is consolidating the foundation of innovation. The practical significance of innovation is to improve the overall quality of professional quality as the core and the process of sublimation, which in the process of the realization, is not a dream, but a return to the actual construction. The relevant content of the subject contest should be based on the basic knowledge of the subject as the foundation of the competition, around the characteristics of the relevant professional to design of the relevant competition, with the help of the discipline competition to grasped and understood the students' subject knowledge, in the course of practice, students should be encouraged to actively think about the enthusiasm of the students, and in practice, reasonably and effectively innovate. Such a subject competition requirements should be in the topic design of the subject contest, in accordance with the use of the relevant content of professional knowledge and the extension of knowledge in the development of related issues. In the setting of related problems, it is not out of the subject's own category, but also to ensure that in the course of the competition, what's more, pay attention to the students' independent design, free exploration, their own practice and independent innovation practice opportunities, such a breakthrough can make college students have the knowledge of the development potential of the show.

College Students' Subject Competition is to Cultivate Students' Innovative and Entrepreneurial Orientation. Aiming at the problem of College Students' academic competition to cultivate students' innovative and entrepreneurial orientation, in the course of the university student's academic competition, there is a different view of the construction of the subject's own knowledge, for example, the competition of economic management is based on the form of actual combat and simulation operation. Under the category of materials science, the corresponding subject competition is the network of steel making competition, in view of the characteristics of the subject, the form of the game is simulated. Taking the Seventh World Finals competition title "pipeline steel refining" as an example, the participants in the two hours must complete the lowest cost of production to meet the quality requirements of pipeline steel. The corresponding mechanical design contest is basically used in the form of the work design + live demonstration to complete. This kind of discipline competition, the biggest knowledge construction is the related discipline knowledge consummation; this kind of improving is for the present university student discipline competition most effective foundation. How to change the form of the subject competition, the final purpose of all the subject competition is improved and created according to improving the ability of college students in innovation and entrepreneurship. So in the process of College Students' academic competition, no matter how the arrangements related to the form, aspects are how to develop, the final standard should stimulate the sense of innovation and Entrepreneurship of college students on that game design concept should be to college students' innovation ability training to do the planning.

The University Student Discipline Competition with the Method of Standardization and Institutionalization. In view of the university student discipline competition taking standardization and institutionalization as the management means, perfecting the organization structure and the system guarantee in the discipline competition will be the future of college students in the subject of competition in the key development of the premise. The discipline competition is the important 
extension condition and the main form of university students' innovation and entrepreneurship practice, which now gradually is applied in many industries and fields, but because now the related system establishment of discipline competition is not perfect, resulting in the competition in the process of implementation, there are still many limitations. Analyzing the current situation of the subject competition, first of all, it should be carried out the unified research and planning of the discipline competition by the relevant education departments of the country, in accordance with the relevant subjects to carry out careful design and research, effective guar anting the institutionalization of the subject contest, standardized and the continuous requirements. In the course of the subject competition, Member of the competition should fully play the input, in the course of the game; effectively enhance the strength of their own situation. And then, from the point of view of higher education, it should set up specialized subject competition management organization, the design of this kind of organization can be effective to correct in accordance with the actual situation of the school and social requirements of the professional discipline competition project development and project rules. In the end, it is supposed to be in the University, the relevant concepts of the subject contest will be effective put in the thought of the university students, so that they can learn the professional knowledge, but also can enhance the ability of competition in the subject.

\section{Summary}

Subject contest problems will be gradually extended as a measure standard of the teaching quality of higher education, In the system of higher education, for the requirements of innovation and entrepreneurship students, now they has been gradually with a greater degree of improvement, in view of this situation, subject contest to improve college students a new entrepreneurial ability has obvious help. In the process of the academic competition, it has a very obvious effect for improving comprehensive ability of college students, which can be accumulated in the future development of the country, for the country to cultivate a comprehensive and outstanding innovative talents.

\section{References}

[1] Liu Li, Zhu Xiaolin, Ma Xiaolin. Promoting college students' innovation and entrepreneurship by subject competition [J].Journal of University of Science and Technology Liaoning, 2014, 02: $180-183+191$.

[2] Li Congrui, Peng Guoping, Chen Weiwei, Xu Aijun Challenge Cup contest as an opportunity to enhance the ability of innovation and Entrepreneurship of college students in Colleges and Universities-- Taking Nanjing University Of Chinese Medicine as an example [J].Science and Technology Innovation Herald, 2014,32:230-231.

[3] Qiu Wenwei. Cultivation and improvement of College Students' innovative and entrepreneurial ability-Function effect based on subject contest [J].Contemporary economy, 2015, 01:107-109.

[4] Wang Hong, Yu Li. Try to analyze secondary school competition and the cultivation of College Students' practical ability in Hainan tourism higher education [J].College education, 2015,03:78-79+97.

[5] He Bing, Qin Ming. Relying on science and technology competition, promoting the cultivation of students' innovative and entrepreneurial ability-Taking the Department of physics and telecommunication engineering of Baise University as an example [J].Journal of Baise University, 2015,06:150-152.

[6] Wang Qi. Research on the subject contest of college students from the perspective of research teaching [D].Northwestern University, 2014 
[7] Cao Yang. Research on innovation and entrepreneurship education in universities and Colleges under the background of transformation of economic development [D]. Northeast Normal University, 2014

[8] Liu Jing. An Empirical Study on the impact of innovation education on College Students' employment in local higher education [D]. Hunan Agricultural University, 2012

[9] Ge Li. Research on the evaluation and promotion strategy of College entrepreneurship education based on CIPP [D].Dalian University of Technology, 2014

[10] Zhang Jinsheng, Wang Zhi. Improve innovation practice education and competition system to enhance the ability of innovation and Entrepreneurship of college students [J] Modern manufacturing technology and equipment, 2010, 06: 66-68. 